\title{
Altered hippocampal function in major depression despite intact structure and resting perfusion.
}

FINKELMEYER, A., NILSSON, J., HE, J., STEVENS, L., MALLER, J.J., MOSS, R.A., SMALL, S., GALLAGHER, P., COVENTRY, K., FERRIER, I.N. and MCALLISTER-WILLIAMS, R.H.

This article has been published in a revised form in Psychological medicine

https://doi.org/10.1017/S0033291716000702. This version is published under a Creative Commons CC-BY-NCND. No commercial re-distribution or re-use allowed. Derivative works cannot be distributed. (C) Cambridge University Press 2016. 


\section{Altered hippocampal function in major depression}

\section{despite intact structure and resting perfusion}

Andreas Finkelmeyer, $\mathrm{PhD}^{1,{ }^{*}}$, Jonna Nilsson, $\mathrm{PhD}^{2}$, Jiabao He, $\mathrm{PhD}^{3}$, Lucy Stevens, $\mathrm{MPhil}^{1}$, Jerome J Maller, $\mathrm{PhD}^{4}$, Rachel Ann Moss, $\mathrm{MSc}^{1}$, Samuel Small, MRes ${ }^{1}$, Peter Gallagher, $\mathrm{PhD}^{1}$, Kenny Coventry, $\mathrm{PhD}^{5}$, Ian Nicol Ferrier, $\mathrm{MD}^{1}$, Richard Hamish McAllister-Williams, MD, $\mathrm{PhD}^{1,6}$

1) Institute of Neuroscience, Newcastle University, Newcastle-upon-Tyne, UK

2) Aging Research Center, Karolinska Institute, Stockholm, Sweden

3) Aberdeen Biomedical Imaging Centre, University of Aberdeen, Aberdeen, UK

4) Monash Alfred Psychiatry Research Centre, Monash University, Melbourne, Australia

5) School of Psychology, University of East Anglia, Norwich, UK

6) Northumberland Tyne and Wear NHS Foundation Trust

*corresponding author address: A. Finkelmeyer, Institute of Neuroscience, Newcastle University, Wolfson Research Centre, Campus for Ageing and Vitality, Newcastle-upon-Tyne, NE4 5PL, UK, email: andreas.finkelmeyer@newcastle.ac.uk

A.F. is supported by Research Capability Funding from the Northumberland-Tyne-and-Wear NHS Foundation Trust awarded to R.H.M.-W.

Word count: 4737 


\begin{abstract}
Background: Hippocampal volume reductions in major depression have been frequently reported. However, evidence for functional abnormalities in the same region in depression has been less clear. We investigated hippocampal function in depression using functional magnetic resonance imaging ( $\mathrm{fMRI}$ ) and neuropsychological tasks tapping spatial memory function, with complementing measures of hippocampal volume and resting blood flow to aid interpretation.
\end{abstract}

Methods: Twenty patients with major depressive disorder (MDD) and a matched group of 20 healthy individuals participated. Participants underwent multimodal magnetic resonance imaging (MRI): fMRI during a spatial memory task, structural MRI and resting blood flow measurements of the hippocampal region using arterial spin labelling (ASL). An offline battery of neuropsychological tests, including several measures of spatial memory, was also completed.

Results: The fMRI analysis showed significant group differences in bilateral anterior regions of the hippocampus. While control participants showed task-dependent differences in blood oxygen level dependent (BOLD) signal, depressed patients did not. No group differences were detected with regard to hippocampal volume or resting blood flow. Patients showed reduced performance in several offline neuropsychological measures. All group differences were independent of differences in hippocampal volume and hippocampal blood flow.

Conclusions: Functional abnormalities of the hippocampus can be observed in patients with MDD even when the volume and resting perfusion in the same region appears normal. This 
suggests that changes in hippocampal function can be observed independently of structural abnormalities of the hippocampus in depression. 


\section{Introduction}

Major depressive disorder (MDD) is associated with reduced hippocampal volumes (Arnone et al., 2012, Campbell and Macqueen, 2004, Palazidou, 2012). Although there is evidence of reduced hippocampal volumes in first-episode, untreated patients(Cole et al., 2011, Zou et al., 2010) and in individuals at familial risk of depression (Amico et al., 2011, Baare et al., 2010, Chen et al., 2010), meta-analyses suggest that volume reductions of the hippocampus are more pronounced with prolonged illness (McKinnon et al., 2009), a higher number of depressive episodes (Videbech and Ravnkilde, 2004) and more severe depression (Arnone et al., 2012, Vakili et al., 2000). Depressed patients also show significant reductions in performance in a large range of cognitive domains (Burt et al., 1995, Rock et al., 2014), including memory and learning, some of which persist in the remitted state (Hasselbalch et al., 2011). Given the prominent role of the hippocampus and surrounding brain structures in memory related functions (Burgess et al., 2002, Lavenex and Banta Lavenex, 2013), structural changes in this region may therefore play a role at least in part in the cognitive dysfunction seen in MDD (Kaymak et al., 2010, Trivedi and Greer, 2014).

Considering the large number of studies investigating hippocampal structure in MDD and the evidence for abnormalities in neuropsychological functions believed to involve the hippocampus, it is surprising that far fewer neuroimaging studies have investigated hippocampal function in this group. Functional magnetic resonance imaging (fMRI) studies of task-related hippocampal activations during memory tasks have been inconsistent showing both increased (Young et al., 2014) and reduced activations (Fairhall et al., 2010, Milne et al., 2012) as well as no significant differences relative to healthy controls (Werner et al., 2009). A magnetoencephalography (MEG) study using a spatial navigation task found 
reduced theta band power in the right hippocampus and parahippocampal area in depressed patients suggesting reduced cortical activity in this region in a spatial task (Cornwell et al., 2010). Earlier $\mathrm{H}_{2}(15) \mathrm{O}$ positron emission tomography (PET) studies showed increased resting cerebral blood flow (CBF) in the hippocampus of depressed patients (Videbech et al., 2002), but reduced blood flow increases during a verbal encoding task (Bremner et al., 2004). A recent study of CBF using arterial spin labelling (ASL) also showed increased resting blood flow in the hippocampus in MDD (Lui et al., 2009). The state of hippocampal function in depression is therefore not clear from the current evidence. Adding to this, the relationships between functional and structural abnormalities of the hippocampus in depressed patients remains largely unexplored. Differences in hippocampal function in depression could be a direct consequence of differences in hippocampal structure but may also emerge independently of such structural differences.

In the present study we investigated if hippocampal function, as measured with fMRI, is altered in depressed patients during performance of a spatial memory task. The task was designed to place specific demands on allocentric spatial memory, which is known to be dependent on the hippocampus (King et al., 2002, Lee et al., 2005). In the allocentric condition of this task, locations are remembered independently of an individual's location and orientation, which is in contrast to the egocentric condition in which locations are remembered relative to the position of the individual. We have previously demonstrated that the allocentric and egocentric conditions results in robust differences in blood-oxygen level dependent (BOLD) signal in the hippocampus in young healthy subjects, which motivates its use as a measure of hippocampal function in the present study (Nilsson et al., 2013). A larger offline battery of neuropsychological tests was also completed to give a 
complete picture of cognitive performance in the patient group relative to the control group.

To allow an exploration of the relationship between hippocampal function and structure, the hippocampi of all subjects were manually traced and were also considered in the analyses. Furthermore, arterial spin labelling (ASL) provided a measure of CBF at rest in the hippocampus to aid in the interpretation of group differences in BOLD signal. Specifically, group differences in BOLD signal could not only be due to differences in neural activity, but may also reflect changes in blood flow, blood volume or oxygen metabolism, all of which contribute to the BOLD signal (Buxton, 2012). Considering previous findings of increased hippocampal CBF in MDD (Lui et al., 2009, Videbech et al., 2002), the ASL measure was therefore included to explore whether potential group differences in BOLD signal could be accounted for by differences in resting CBF.

The present study therefore set out to answer the following main questions: 1) Do depressed patients exhibit abnormal hippocampal function relative to healthy controls, as evidenced by an altered BOLD signal in response to a spatial memory task that place demands on allocentric and egocentric memory systems? 2) Can such group differences in task-related BOLD signal be explained by differences in hippocampal volume or resting CBF?

\section{Methods}

\section{Participants}

A sample of 20 depressed patients and 20 healthy controls were recruited via their consultant psychiatrists or online advertising to participate in the study. Presence or absence of MDD diagnosis was confirmed via Mini International Neuropsychiatric Interview 
(MINI) (Sheehan et al., 1998). Patients were excluded if they had any other Axis 1 disorders other than anxiety, had previously received electroconvulsive therapy or had a change in psychiatric medication in the last four weeks. To take part, patients were required to have a score of 16 or above on the Hamilton Depression Scale (HAM-D)(Williams et al., 2008). Healthy controls were excluded if they or a first-degree relative had a history of psychiatric illness or they had a score of 5 or above on the HAM-D. This meant to ensure that controls were free of even mild depressive symptoms. Patients and healthy controls were excluded from the study if they were dependent on or abusing alcohol or other drugs in the past 12 months. Individuals with conditions contraindicative to MRI were excluded from the study. All participants were right-handed.

In both groups, depressed mood and anxiety were assessed using the Beck Depression Inventory (BDI)(Beck et al., 1961) and the State and Trait Anxiety Inventory (STAI)(Spielberger, 1983). For patients, age of onset, number of episodes, illness duration and current medication regime were determined via retrospective self-report. Pre-morbid verbal IQ was determined using the National Adult Reading Test (NART)(Nelson and Willison, 1991). Table 1 shows patient and healthy control sample characteristics. Groups were matched in terms of age, sex and premorbid IQ.

The research was conducted in accordance with the Declaration of Helsinki. All participants provided written informed consent and the study was approved by the local Research Ethics Committee.

[TABLE 1 HERE] 
Participants completed a number of neuropsychological tasks encompassing a range of cognitive functions many of which are believed to engage the hippocampus. The battery included tasks of visuospatial and verbal memory: the object-relocation task (Kessels et al., 1999), the Newcastle Spatial Memory Test, a computerized adaptation of a task previously described by other groups as "box task"(van Asselen et al., 2005) or "executive golf" task (Feigenbaum et al., 1996), the visual patterns test (Della Sala et al., 1997), digit span, and the Rey Auditory Verbal Learning Test (Schmidt, 1996). Two additional tasks examined primarily executive function: the Stroop task (Golden and Freshwater, 2002) and the Trail Making Test (Tombaugh, 2004).

\section{Spatial Memory fMRI task}

For the fMRI scan participants performed a spatial memory task, which relied on spatial knowledge of a previously learned artificial environment which comprised a circular arena with seven spatial landmarks placed at equidistance on the walls. Prior to the scan session, participants were familiarized with this environment using a scale model. All participants were able to remember all landmark positions before entering the scanner.

During the scan, participants viewed computer renderings of the arena from a viewpoint above and slightly outside the arena (see Figure 1). Each trial consisted of three phases: encoding, delay and recall. In the encoding phase participants were shown the arena with a single pole marking the spatial location to be remembered. In the recall phase, participants were required to recall this location by making a forced choice between two marked locations. Crucially, participants were told that during the delay phase either the walls of the arena would rotate while their own position remained fixed or that their own position would rotate around the perimeter of the arena. Whereas the wall rotation forced 
participants to rely on egocentric spatial relations to retrieve the target position, a change in their own position forced them to rely on allocentric spatial relations between the landmarks and the target. Since the rotations were not shown on the screen, participants were made aware of the rotation type via a verbal cue during the delay phase ("walls" for wall rotation or "you" for rotation of viewer location, see Figure 1). A third, control condition had identical trial structure and visuomotor demands but did not require participants to encode or recall spatial locations. Here, the empty arena was shown during the encoding phase and during the retrieval phase one of the two test locations was highlighted and participants simply had to press the button that corresponded to this highlighted location. Participants completed a total of 36 trials per condition (egocentric, allocentric, control) split into two runs. In addition, there were 36 baseline periods ( 9 seconds each) throughout the task, during which a fixation cross was presented. The length of each run was approximately 14 minutes.

[FIGURE 1 HERE]

Image acquisition and analysis

Scans took place on a 3T Achieva MR scanner (Philips Healthcare, Best, NL), using an 8channel head coil as receiver. High-resolution T1 weighted anatomical images were acquired using a standard clinical 3D MPRAGE sequence (TR/TE=8.5/4.6ms, 320x320 matrix size, 225 slices, voxel size $0.8 \mathrm{~mm}$ isotropic). This was followed by two runs of the functional scan, using a gradient-echo echo-planar-imaging sequence $(T E=30 \mathrm{~ms}, T R=2600 \mathrm{~ms}$, flip angle $=65^{\circ}$, voxel size $2.5 \mathrm{~mm} \times 2.5 \mathrm{~mm} \times 3.5 \mathrm{~mm}, 40$ axial slices, 325 volumes). Lastly, a set of flow-sensitive alternating inversion recovery (FAIR) ASL scans that used an improved inversion pulse (He and Blamire, 2010) were performed (TR=4000ms, TE $=23 \mathrm{~ms}, 4 \mathrm{~mm} \times 4 \mathrm{~mm}$ 
$\times 6 \mathrm{~mm}$ voxel size, $64 \times 64$ matrix size, inversion time $\mathrm{Tl}=1700 \mathrm{~ms}, 40$ tag-control pairs;

additional inversion times were used for $M_{0}$ calculations), with four axial slices positioned along the length of the hippocampus.

Manual tracings of the hippocampus in both hemispheres were performed in Analyze 12.0 (Brain Imaging Resource, Mayo Clinic, MN) by an experienced tracer (JJM) who was blind to the status of the scans as patient or control. Tracings were performed on coronal slices and verified from axial and sagittal perspectives. The hippocampus was divided into an anterior region (including the body and head) and a posterior region (Maller et al., 2007). Hippocampal volumes were then calculated for the different subregions. To account for differences in head size, hippocampal volumes were divided by total intracranial volume which was determined from segmentation of the anatomical scan using SPM8 (Wellcome Centre for Neuroimaging, University College London, UK) in Matlab R2010b (The MathWorks Inc., Natick, MA, USA). Tracings also served as region-of-interest (ROI) definitions for the analysis of the fMRI and ASL scan data.

SPM8 was also used for the fMRI image analysis. Pre-processing included slice-time correction, realignment/unwarping and co-registration with the anatomical scan. First-level models were calculated in native space to allow for the extraction of contrast estimates from the individually traced hippocampus ROIs. They included two regressors for the encoding phase (encoding vs control), three regressors for the delay phase and three regressors for the recall phases (allocentric recall, egocentric recall, control). The regressors for egocentric and allocentric recall further included the trial specific reaction time as parametric modulator. All regressors were constructed as (short) boxcar functions of their respective event onsets and durations ( 3 s encoding, 3.75s delay, 5 s retrieval) convolved 
with the canonical hemodynamic response function implemented in SPM8. Movement parameters were included as regressors of no interest. One patient had excessively moved during the fMRI scans (volume-to-volume motion exceeded half a voxel size) and was excluded from further $\mathrm{FMRI}$ data analysis.

The primary interest of the present paper was the difference between the allocentric and egocentric recall phase. Following the estimation of the first-level model, we therefore computed contrast images that subtracted the egocentric from the allocentric recall phase estimates. Average values for the hippocampus ROls were then extracted from these Allocentric-versus-Egocentric (AvE) contrast images for statistical analysis. An additional whole-brain analysis for this contrast is reported in the supplementary material.

ASL images were first re-sliced to $2 \mathrm{~mm}$ isotropic voxel size, then re-aligned to the first scan and manually co-registered with the anatomical scan using rigid-body transformations. All subsequent ASL processing was based on extracted signal levels from the hippocampus ROIs and from grey matter and white matter segments. The average tag-control signal level difference of the FAIR scan was used to calculate blood perfusion values according to a standard kinetic model (Buxton et al., 1998). Additional parameters for these calculations (e.g. T1 of arterial blood) were based on published findings (Lu et al., 2004, Maclntosh et al., 2010, Roberts et al., 1996).

\section{Statistical analyses}

Statistical analyses were performed in SPSS Statistics 21 (IBM, New York, NY, USA). Initial group comparisons of the AvE contrast, volumes and some neuropsychological measures were performed using two-tailed, independent sample t-tests, adjusted for unequal 
variance if necessary. Neuropsychological measures that provided counts out of a fixed number of trials or items as a dependent measure were analyzed using Generalized Linear Models with a binary logistic, binomial distribution model. Because sex differences in CBF have previously been reported (Parkes et al., 2004), any analysis involving regional CBF included sex as a covariate. Additional group comparisons included either (regional) hippocampal volumes (AvE contrast, neuropsychological measures) or regional CBF (AvE contrast) as covariates to eliminate their potential impact on the group differences.

\section{Results}

fMRI results

Table 2 shows the results of the extracted AvE contrast for each of the four hippocampus ROIs. There were significant group differences for the AvE contrast in the two anterior ROIs, with statistical trends in the same direction for the posterior regions (see Table 2). As shown in Figure 2, which shows BOLD signals of the two conditions relative to the control condition, this group difference appears to be driven by the control group. Compared to the control condition, controls showed reductions in BOLD signal in the allocentric condition in bilateral anterior regions (left: $p=.030$, right: $p=.001$ ) and right posterior $\mathrm{ROI}(\mathrm{p}=.006)$, but not the left posterior ROI ( $p=.467)$, whereas no significant change from the control condition was observed in any ROI during the egocentric condition (all p>.211). The patient group did not show significant differences in either the egocentric or the allocentric condition relative to the control condition in any of the ROIs (all p>.570). A whole-brain analysis across both groups showed widespread BOLD signal differences in the AvE contrast, but no significant group differences (see supplementary material). In the control group, clusters of negative 
AvE contrast can be found in bilateral anterior hippocampus at an uncorrected level of $\mathrm{p}<.001$ (see supplementary material).

[TABLE 2 HERE]

[FIGURE 2 HERE]

To investigate if the group differences are specific to the hippocampus regions, we extracted contrast estimates from three additional ROIs that also showed negative BOLD signal during the allocentric condition and a negative AvE contrast (at least $p<0.001$, uncorrected, in whole-brain analysis). These included a cluster in the posterior cingulate cortex (MNI: -8, 52, 30; 137 voxels), a cluster in the rostral anterior cingulate cortex (MNI: -6, 38, -6; 206 voxels) and a cluster in the medial prefrontal cortex (MNI: -2, 64, 10; 211 voxels). Comparing the AvE contrast in these regions between patients and controls showed no significant differences (all $p>0.385$ ).

\section{Behavioral performance}

Test results of the neuropsychological tasks are shown in Table 3. Significant differences between the groups were seen in the majority of the tasks measuring verbal and spatial memory. In contrast to our earlier study in young healthy controls, in which performance in the egocentric condition of the fMRI task was near perfect ( $96 \%$ correct), 3 patients and 5 controls had near or sub-random task performance in this condition in the present study (less than 23 of 36 trials correct). This likely indicates non-compliance with or a misunderstanding of the instructions for this particular condition. We therefore excluded these participants from the analysis of behavioral performance of the fMRI task. As this may have also influenced the main fMRI findings, we repeated the above ROI analysis with these 
participants excluded. This did not fundamentally alter the results presented above (see supplementary information). There were no significant group differences in the behavioral performance of the spatial memory fMRI task, but the otherwise expected task effects (see supplementary material for detailed results).

\section{[TABLE 3 HERE]}

\section{Hippocampal volumes}

The comparison of normalized hippocampal volumes showed no significant differences between patients and controls for any of the individual ROls or for any combined volume (all $p>$.274). Detailed results are given in the supplementary material.

\section{ASL results}

Group had no significant effect on CBF in any of the hippocampal regions (all $p>0.287$ ) or for the overall grey and white matter segments of the imaged slab. There were significant main effects of sex in all but one region (left posterior, $p=.105$ ), with females showing higher CBF than males. See supplementary material for detailed ASL results.

\section{Controlling for volume or CBF}

Including the respective regional volume as a covariate in the group comparisons of the AvE contrast did not alter the earlier findings strongly. The significant group effect in the two anterior ROIs (left: $\mathrm{p}=.029$, right: $\mathrm{p}=.023$ ) and the statistical trend in the right posterior ROI $(p=.096)$ remained. Furthermore, the previous trend-level group difference in the left posterior ROI was no statistically significant $(p=.038)$. Controlling for regional CBF and sex had little influence on the earlier AvE group effects although their $p$-values were generally 
slightly increased (left anterior: $p=.048$, right anterior: $p=.074$, left posterior: $p=.138$, right posterior: $\mathrm{p}=.083$ ). Previously significant group differences in the neuropsychological tasks remained significant when covarying for differences in the normalized volume of the entire hippocampus.

\section{Discussion}

The present study investigated hippocampal function and its relationship to hippocampal structure in major depression using multimodal MR imaging and neuropsychological testing. Our ROI analysis of the BOLD signal during the fMRI task showed that the contrast between allocentric and egocentric recall conditions was significantly different between the two groups in bilateral anterior hippocampus: Healthy controls showed a reduced BOLD signal during the allocentric condition relative to the egocentric condition. In contrast, in patients there was no reduction in BOLD signal in the allocentric compared to the egocentric condition in any of the ROls, which was also not different from the control condition.

The reduction in BOLD signal in the allocentric condition relative to the egocentric condition in the control group is consistent with our previous findings in healthy young participants (Nilsson et al., 2013). This demonstrates that the level of hippocampal engagement differs between these two conditions. This BOLD signal decrease may signify a task-related reduction in hippocampal neuronal activity in response to the allocentric condition, though we have previously discussed alternative interpretations (Nilsson et al., 2013). Thus, whilst this negative-going BOLD signal is difficult to interpret, it is nonetheless evidence that the different task conditions result in differential activity in the anterior hippocampus in control subjects. 
In contrast, depressed patients showed no change in BOLD signal from the control condition in either the allocentric or egocentric condition in any of the hippocampal regions. Accordingly, this finding can be described as a lack of modulation of hippocampal activity in response to task demands in the patient group. Similar reduced modulations of hippocampal BOLD in response to task demands have been observed in previous studies in depression although they are often described as reduced increases in activity in the patient group (Bremner et al., 2004, Fairhall et al., 2010, Milne et al., 2012). Whilst the relative nature of the BOLD signal prevents any conclusions regarding the absolute levels of neuronal activity, the current results demonstrate that the systematic, task-related differences in underlying hippocampal activity in healthy controls are absent in depressed patients.

To test the specificity of this finding to the hippocampus we investigated three other ROIs that also showed strong negative BOLD signal in the allocentric condition, both compared to control and the egocentric condition. These regions are frequently associated with the socalled default mode network (Raichle and Snyder, 2007), which shows reductions in BOLD signal during a wide variety of tasks and has been argued to be dysfunctional in depression (Dutta et al., 2014). Analyses of these additional ROls did not indicate a difference between patients and controls in the amount of reduction of BOLD signal during allocentric recall. The observed group effect in the hippocampus therefore does not appear to be the reflection of a more generic alteration of default-mode network activity in MDD. Furthermore, analyses that included hippocampal volumes or resting blood flow as a covariate did not fundamentally alter the results, indicating that the differential pattern of 
BOLD signal in the patient group cannot be explained by volumetric differences or by alterations in hippocampal blood flow.

Beyond the hippocampus, the fMRI task recruits a large network of brain regions, including large parts of the parietal lobe, all of which contribute to the task (Nilsson et al., 2013). At the whole brain level we did not observe any significant group differences in BOLD signal. While this could be due to the lower sensitivity of a whole-brain analysis, it suggests that patients did not use fundamentally different brain regions to perform the task. In line with such an argument, there were also no significant behavioral differences between the groups in any of the conditions of the fMRI task, but both groups showed large differences between the two conditions and (expected) increases in error rate and response time with rotation angle in the allocentric but not the egocentric condition. Thus, the observed group difference in hippocampal BOLD did not translate into differential performance in the task. This also suggests that group differences in BOLD signal were not due to other task-related factors (e.g. motivation, perceived difficulty). It is worth noting that the fMRI task was developed primarily to investigate differences in hippocampal function and not to detect behavioral differences.

In support of the limited sensitivity of the task for detecting behavioral group differences in the scanner, the patient group demonstrated impaired performance on a number of spatial and verbal memory tasks performed outside the scanner, which is consistent with previous research (Hinkelmann et al., 2009, Ravnkilde et al., 2002). One explanation for this discrepancy could be that compared to the fMRI task, the offline spatial measures required participants to remember a greater number of locations ("object-location binding", "position-only memory") and to remember locations over longer time periods ("between- 
search errors"). It is conceivable that the higher cognitive load in the offline spatial memory measures resulted in an increased sensitivity for detecting group differences. Furthermore, it should be emphasized that the present study is not the first to demonstrate an altered modulation of hippocampal activity in MDD in the absence of behavioral group differences (Bremner et al., 2004, Fairhall et al., 2010).

Contrary to previous findings we did not observe decreases in hippocampal volume in the patient group. This is perhaps not surprising given that a recent meta-analysis on this topic has shown only small to medium effect sizes for hippocampal volume reductions in depression (effect size approx. -0.3) with significant heterogeneity across studies (Arnone et al., 2012). It has also been suggested that pharmacological treatment may counteract hippocampal volume reductions in MDD (Arnone et al., 2013). Since all but one patient of the current study were medicated this may have contributed to the fact that we did not find volume differences. Furthermore, it has been suggested that such reductions mostly occur in depressed patients who have been ill for some time or who have had multiple episodes (McKinnon et al., 2009). While a number of our patients certainly fell into this category, there was considerable heterogeneity in terms of clinical characteristics and age in the present sample. This, combined with the relatively moderate sample size means that the power to detect small volume differences in the present study was likely insufficient.

It is also noteworthy that, similar to the previous neuroimaging studies of hippocampal function in depression (Bremner et al., 2004, Fairhall et al., 2010, Milne et al., 2012), our group difference in BOLD signal was located in anterior regions of the hippocampus, whereas volumetric findings in depression tend to show differences in more posterior regions of the hippocampus (Cole et al., 2010, Maller et al., 2007, Maller et al., 2012, 
Neumeister et al., 2005). It is possible that the different spatial resolutions of the anatomical and functional scans play a role in this apparent discrepancy. The narrow and elongated shape of the hippocampus may make the posterior part of the hippocampus more sensitive to detecting morphological changes in anatomical scans with high spatial resolution, whereas it would increase the influence of partial volume effects in lower resolution functional scans. If the same pathophysiological process that is responsible for the structural changes seen in other studies was also responsible for the functional changes seen in the current study, it may mean that functional changes can precede changes in structure, which is why we were able to detect the former but not the latter. Alternatively, it is possible that independent pathological processes are at work, with some responsible for volume changes in posterior parts of the hippocampus, while others are responsible for functional changes in anterior hippocampus. To reduce the potential influence of partial volume effects, replications with higher-resolution functional scans would be necessary. Such research should also involve a functional task that produces task-related BOLD changes in the posterior hippocampus.

The ASL based measure of hippocampal resting blood flow did not show differences between the two groups. In contrast, sex had a significant effect on CBF in nearly all investigated regions. Such differences between males and females have consistently been reported using both MR based (Liu et al., 2012, Parkes et al., 2004) and PET methodologies (Henriksen et al., 2013). This suggests that our ASL methodology was sensitive enough to detect some group differences, but if any differences in CBF between our patient and control group existed, they were too small to be detected in our sample. The previous study showing hippocampal hyperperfusion in depression using PET (Videbech et al., 2002) 
studied a patient sample that was considerably different from the present study. Whereas patients in the PET study were all inpatients and described as "rather acutely depressed" ( $p$. 38), our sample consisted of outpatients that tended to have been ill for at least some time. The PET study also showed that the differences were more pronounced in patients who were either un-medicated or had only received medication for less than 1 week (Videbech et al., 2002). A more recent PET study that found increased resting blood flow in the left parahippocampal gyrus in a whole-brain analysis also only studied un-medicated patients (Monkul et al., 2012). In our sample, apart from one un-medicated patient, all patients had been on stable medication for at least four weeks prior to the scan. It can be speculated that blood flow changes in the hippocampus are restricted to rather short periods at the beginning of an acute depressive episode and are reversed by medication. In support of this, a large study using ASL to measure CBF in acutely depressed patients found hippocampal hyperperfusion only in a group of non-treatment-refractory patients, both compared to treatment-refractory patients and to controls (Lui et al., 2009). It was outside the scope of our study to determine any treatment response of our patients, thus our sample is likely a mix of treatment-refractory and non-refractory patients.

In summary, we have presented evidence for reduced modulation of hippocampal activity during a spatial memory task in depressed patients relative to healthy controls. This reduced modulation could not be accounted for by differences in hippocampal structure or resting cerebral blood flow in the same region, suggesting that volumetric or baseline hemodynamic differences are not underlying the functional differences. Whether or not these differences in hippocampal function are reflective of an early degenerative process that has yet to result in observable volumetric reductions can only be answered with 
longitudinal investigations, which could also answer the question if and when such functional abnormalities may be reliably linked to behavioral impairments. 


\section{References}

Amico, F., Meisenzahl, E., Koutsouleris, N., Reiser, M., Moller, H. J. \& Frodl, T. (2011). Structural $\mathrm{MRI}$ correlates for vulnerability and resilience to major depressive disorder. Journal of psychiatry \& neuroscience : JPN 36, 15-22.

Arnone, D., McIntosh, A. M., Ebmeier, K. P., Munafo, M. R. \& Anderson, I. M. (2012). Magnetic resonance imaging studies in unipolar depression: systematic review and meta-regression analyses. European neuropsychopharmacology : the journal of the European College of Neuropsychopharmacology 22, 1-16.

Arnone, D., McKie, S., Elliott, R., Juhasz, G., Thomas, E. J., Downey, D., Williams, S., Deakin, J. F. \& Anderson, I. M. (2013). State-dependent changes in hippocampal grey matter in depression. Molecular psychiatry 18, 1265-72.

Baare, W. F., Vinberg, M., Knudsen, G. M., Paulson, O. B., Langkilde, A. R., Jernigan, T. L. \& Kessing, L. V. (2010). Hippocampal volume changes in healthy subjects at risk of unipolar depression. Journal of psychiatric research 44, 655-62.

Beck, A. T., Ward, C. H., Mendelson, M., Mock, J. \& Erbaugh, J. (1961). An inventory for measuring depression. Archives of general psychiatry 4, 561-71.

Bremner, J. D., Vythilingam, M., Vermetten, E., Vaccarino, V. \& Charney, D. S. (2004). Deficits in hippocampal and anterior cingulate functioning during verbal declarative memory encoding in midlife major depression. The American journal of psychiatry 161, 637-45.

Burgess, N., Maguire, E. A. \& O'Keefe, J. (2002). The human hippocampus and spatial and episodic memory. Neuron 35, 625-41.

Burt, D. B., Zembar, M. J. \& Niederehe, G. (1995). Depression and memory impairment: a metaanalysis of the association, its pattern, and specificity. Psychological bulletin 117, 285-305.

Buxton, R. B. (2012). Dynamic models of BOLD contrast. Neurolmage 62, 953-61.

Buxton, R. B., Frank, L. R., Wong, E. C., Siewert, B., Warach, S. \& Edelman, R. R. (1998). A general kinetic model for quantitative perfusion imaging with arterial spin labeling. Magnetic resonance in medicine 40, 383-96.

Campbell, S. \& Macqueen, G. (2004). The role of the hippocampus in the pathophysiology of major depression. Journal of psychiatry \& neuroscience : JPN 29, 417-26.

Chen, M. C., Hamilton, J. P. \& Gotlib, I. H. (2010). Decreased hippocampal volume in healthy girls at risk of depression. Archives of general psychiatry 67, 270-6.

Cole, J., Costafreda, S. G., McGuffin, P. \& Fu, C. H. (2011). Hippocampal atrophy in first episode depression: a meta-analysis of magnetic resonance imaging studies. Journal of affective disorders 134, 483-7.

Cole, J., Toga, A. W., Hojatkashani, C., Thompson, P., Costafreda, S. G., Cleare, A. J., Williams, S. C., Bullmore, E. T., Scott, J. L., Mitterschiffthaler, M. T., Walsh, N. D., Donaldson, C., Mirza, M., Marquand, A., Nosarti, C., McGuffin, P. \& Fu, C. H. (2010). Subregional hippocampal deformations in major depressive disorder. Journal of affective disorders 126, 272-7.

Cornwell, B. R., Salvadore, G., Colon-Rosario, V., Latov, D. R., Holroyd, T., Carver, F. W., Coppola, R., Manji, H. K., Zarate, C. A., Jr. \& Grillon, C. (2010). Abnormal hippocampal functioning and impaired spatial navigation in depressed individuals: evidence from whole-head magnetoencephalography. The American journal of psychiatry 167, 836-44.

Della Sala, S., Gray, C., Baddeley, A. \& Wilson, L. (1997). Visual Patterns Test: a test of short-term visual recall. Thames Valley Test Company: Bury St Edmunds.

Dutta, A., McKie, S. \& Deakin, J. F. (2014). Resting state networks in major depressive disorder. Psychiatry research 224, 139-51.

Fairhall, S. L., Sharma, S., Magnusson, J. \& Murphy, B. (2010). Memory related dysregulation of hippocampal function in major depressive disorder. Biological psychology 85, 499-503. 
Feigenbaum, J. D., Polkey, C. E. \& Morris, R. G. (1996). Deficits in spatial working memory after unilateral temporal lobectomy in man. Neuropsychologia 34, 163-76.

Golden, C. J. \& Freshwater, S. (2002). The Stroop color and word test: A manual for clinical and experimental uses. Stoelting Co: Chicaco.

Hasselbalch, B. J., Knorr, U. \& Kessing, L. V. (2011). Cognitive impairment in the remitted state of unipolar depressive disorder: a systematic review. Journal of affective disorders 134, 20-31.

He, J. \& Blamire, A. M. (2010). Application of variable-rate selective excitation pulses for spin labeling in perfusion MRI. Magnetic resonance in medicine 63, 842-7.

Henriksen, O. M., Kruuse, C., Olesen, J., Jensen, L. T., Larsson, H. B., Birk, S., Hansen, J. M., Wienecke, T. \& Rostrup, E. (2013). Sources of variability of resting cerebral blood flow in healthy subjects: a study using (1)(3)(3)Xe SPECT measurements. Journal of cerebral blood flow and metabolism : official journal of the International Society of Cerebral Blood Flow and Metabolism 33, 787-92.

Hinkelmann, K., Moritz, S., Botzenhardt, J., Riedesel, K., Wiedemann, K., Kellner, M. \& Otte, C. (2009). Cognitive impairment in major depression: association with salivary cortisol. Biological psychiatry 66, 879-85.

Kaymak, S. U., Demir, B., Senturk, S., Tatar, I., Aldur, M. M. \& Ulug, B. (2010). Hippocampus, glucocorticoids and neurocognitive functions in patients with first-episode major depressive disorders. European archives of psychiatry and clinical neuroscience 260, 217-23.

Kessels, R. P. C., Postma, A. \& de Haan, E. H. F. (1999). Object Relocation: A program for setting up, running, and analyzing experiments on memory for object locations. Behav Res Meth Ins C 31, 423428.

King, J. A., Burgess, N., Hartley, T., Vargha-Khadem, F. \& O'Keefe, J. (2002). Human hippocampus and viewpoint dependence in spatial memory. Hippocampus 12, 811-20.

Lavenex, P. \& Banta Lavenex, P. (2013). Building hippocampal circuits to learn and remember: insights into the development of human memory. Behavioural brain research 254, 8-21.

Lee, A. C., Buckley, M. J., Pegman, S. J., Spiers, H., Scahill, V. L., Gaffan, D., Bussey, T. J., Davies, R. R., Kapur, N., Hodges, J. R. \& Graham, K. S. (2005). Specialization in the medial temporal lobe for processing of objects and scenes. Hippocampus 15, 782-97.

Liu, Y., Zhu, X., Feinberg, D., Guenther, M., Gregori, J., Weiner, M. W. \& Schuff, N. (2012). Arterial spin labeling MRI study of age and gender effects on brain perfusion hemodynamics. Magnetic resonance in medicine $68,912-22$.

Lu, H., Clingman, C., Golay, X. \& van Zijl, P. C. (2004). Determining the longitudinal relaxation time (T1) of blood at 3.0 Tesla. Magnetic resonance in medicine 52, 679-82.

Lui, S., Parkes, L. M., Huang, X., Zou, K., Chan, R. C., Yang, H., Zou, L., Li, D., Tang, H., Zhang, T., Li, X., Wei, Y., Chen, L., Sun, X., Kemp, G. J. \& Gong, Q. Y. (2009). Depressive disorders: focally altered cerebral perfusion measured with arterial spin-labeling MR imaging. Radiology 251, 476-84.

MacIntosh, B. J., Filippini, N., Chappell, M. A., Woolrich, M. W., Mackay, C. E. \& Jezzard, P. (2010). Assessment of arterial arrival times derived from multiple inversion time pulsed arterial spin labeling MRI. Magnetic resonance in medicine 63, 641-7.

Maller, J. J., Daskalakis, Z. J. \& Fitzgerald, P. B. (2007). Hippocampal volumetrics in depression: the importance of the posterior tail. Hippocampus 17, 1023-7.

Maller, J. J., Daskalakis, Z. J., Thomson, R. H., Daigle, M., Barr, M. S. \& Fitzgerald, P. B. (2012). Hippocampal volumetrics in treatment-resistant depression and schizophrenia: the devil's in de-tail. Hippocampus 22, 9-16.

McKinnon, M. C., Yucel, K., Nazarov, A. \& MacQueen, G. M. (2009). A meta-analysis examining clinical predictors of hippocampal volume in patients with major depressive disorder. Journal of psychiatry \& neuroscience : JPN 34, 41-54.

Milne, A. M., MacQueen, G. M. \& Hall, G. B. (2012). Abnormal hippocampal activation in patients with extensive history of major depression: an fMRI study. Journal of psychiatry \& neuroscience : JPN 37, 28-36. 
Monkul, E. S., Silva, L. A., Narayana, S., Peluso, M. A., Zamarripa, F., Nery, F. G., Najt, P., Li, J., Lancaster, J. L., Fox, P. T., Lafer, B. \& Soares, J. C. (2012). Abnormal resting state corticolimbic blood flow in depressed unmedicated patients with major depression: a (15)O-H(2)O PET study. Human brain mapping 33, 272-9.

Nelson, H. E. \& Willison, J. (1991). National Adult Reading Test (NART). NFER-NELSON: Berkshire, UK.

Neumeister, A., Wood, S., Bonne, O., Nugent, A. C., Luckenbaugh, D. A., Young, T., Bain, E. E., Charney, D. S. \& Drevets, W. C. (2005). Reduced hippocampal volume in unmedicated, remitted patients with major depression versus control subjects. Biological psychiatry 57, 935-7.

Nilsson, J., Ferrier, I. N., Coventry, K., Bester, A. \& Finkelmeyer, A. (2013). Negative BOLD response in the hippocampus during short-term spatial memory retrieval. Journal of cognitive neuroscience 25, 1358-71.

Palazidou, E. (2012). The neurobiology of depression. British medical bulletin 101, 127-45.

Parkes, L. M., Rashid, W., Chard, D. T. \& Tofts, P. S. (2004). Normal cerebral perfusion measurements using arterial spin labeling: reproducibility, stability, and age and gender effects. Magnetic resonance in medicine 51, 736-43.

Raichle, M. E. \& Snyder, A. Z. (2007). A default mode of brain function: a brief history of an evolving idea. Neurolmage 37, 1083-90; discussion 1097-9.

Ravnkilde, B., Videbech, P., Clemmensen, K., Egander, A., Rasmussen, N. A. \& Rosenberg, R. (2002). Cognitive deficits in major depression. Scandinavian journal of psychology 43, 239-51.

Roberts, D. A., Rizi, R., Lenkinski, R. E. \& Leigh, J. S., Jr. (1996). Magnetic resonance imaging of the brain: blood partition coefficient for water: application to spin-tagging measurement of perfusion.

Journal of magnetic resonance imaging : JMRI 6, 363-6.

Rock, P. L., Roiser, J. P., Riedel, W. J. \& Blackwell, A. D. (2014). Cognitive impairment in depression: a systematic review and meta-analysis. Psychological medicine 44, 2029-40.

Schmidt, M. (1996). Rey auditory and verbal learning test: a handbook. Western Psychological Services: Los Angeles.

Sheehan, D. V., Lecrubier, Y., Sheehan, K. H., Amorim, P., Janavs, J., Weiller, E., Hergueta, T., Baker, R. \& Dunbar, G. C. (1998). The Mini-International Neuropsychiatric Interview (M.I.N.I.): the development and validation of a structured diagnostic psychiatric interview for DSM-IV and ICD-10. The Journal of clinical psychiatry 59 Suppl 20, 22-33;quiz 34-57.

Spielberger, C. D. (1983). Manual for the State-Trait Anxiety Inventory (Form Y). Mind Gardens: Palo Alto, CA, USA.

Tombaugh, T. N. (2004). Trail Making Test A and B: Normative data stratified by age and education. .19, pp.

Trivedi, M. H. \& Greer, T. L. (2014). Cognitive dysfunction in unipolar depression: implications for treatment. Journal of affective disorders 152-154, 19-27.

Vakili, K., Pillay, S. S., Lafer, B., Fava, M., Renshaw, P. F., Bonello-Cintron, C. M. \& Yurgelun-Todd, D. A. (2000). Hippocampal volume in primary unipolar major depression: a magnetic resonance imaging study. Biological psychiatry 47, 1087-90.

van Asselen, M., Kessels, R. P., Wester, A. J. \& Postma, A. (2005). Spatial working memory and contextual cueing in patients with Korsakoff amnesia. Journal of clinical and experimental neuropsychology 27, 645-55.

Videbech, P. \& Ravnkilde, B. (2004). Hippocampal volume and depression: a meta-analysis of MRI studies. The American journal of psychiatry 161, 1957-66.

Videbech, P., Ravnkilde, B., Pedersen, T. H., Hartvig, H., Egander, A., Clemmensen, K., Rasmussen, N. A., Andersen, F., Gjedde, A. \& Rosenberg, R. (2002). The Danish PET/depression project: clinical symptoms and cerebral blood flow. A regions-of-interest analysis. Acta psychiatrica Scandinavica 106, 35-44. 
Werner, N. S., Meindl, T., Materne, J., Engel, R. R., Huber, D., Riedel, M., Reiser, M. \& Hennig-Fast, K. (2009). Functional MRI study of memory-related brain regions in patients with depressive disorder. Journal of affective disorders 119, 124-31.

Williams, J. B., Kobak, K. A., Bech, P., Engelhardt, N., Evans, K., Lipsitz, J., Olin, J., Pearson, J. \& Kalali, A. (2008). The GRID-HAMD: standardization of the Hamilton Depression Rating Scale. International clinical psychopharmacology 23, 120-9.

Young, K. D., Bellgowan, P. S., Bodurka, J. \& Drevets, W. C. (2014). Neurophysiological correlates of autobiographical memory deficits in currently and formerly depressed subjects. Psychological medicine 44, 2951-63.

Zou, K., Deng, W., Li, T., Zhang, B., Jiang, L., Huang, C., Sun, X. \& Sun, X. (2010). Changes of brain morphometry in first-episode, drug-naive, non-late-life adult patients with major depression: an optimized voxel-based morphometry study. Biological psychiatry 67, 186-8. 


\section{Acknowledgements}

We graciously acknowledge the help of the staff of the Newcastle Magnetic Resonance Centre, Newcastle University, in conducting this research.

\section{Financial support}

A.F. is supported by Research Capability Funding from the Northumberland-Tyne-and-Wear NHS Foundation Trust awarded to R.H.M.-W.

\section{Conflict of interest}

None of the authors report biomedical financial interests or potential conflicts of interest that are relevant to the subject matter of this manuscript.

\section{Ethical standards}

The authors assert that all procedures contributing to this work comply with the ethical standards of the relevant national and institutional committees on human experimentation and with the Helsinki Declaration of 1975, as revised in 2008. 


\section{Tables}

Table 1: Participant characteristics

Table 2: Hippocampus-ROI fMRI results

Table 3: Results of neuropsychological testing 


\section{Figure legends}

Figure 1: Task design and example trials for the allocentric and egocentric condition. Not shown is that the verbal cue during the delay was displayed on top of a scrambled version of the scene. In both examples the orange/darker dot marks the correct location and the white dot is the distractor. During "control" trials, no pole was shown at encoding and during recall one of the two colored dots was marked with a pole.

Figure 2: BOLD signal beta coefficients of the four hippocampus ROIs for patients and control participants for the allocentric (Allo) and egocentric (Ego) retrieval phase. 
Figure 1

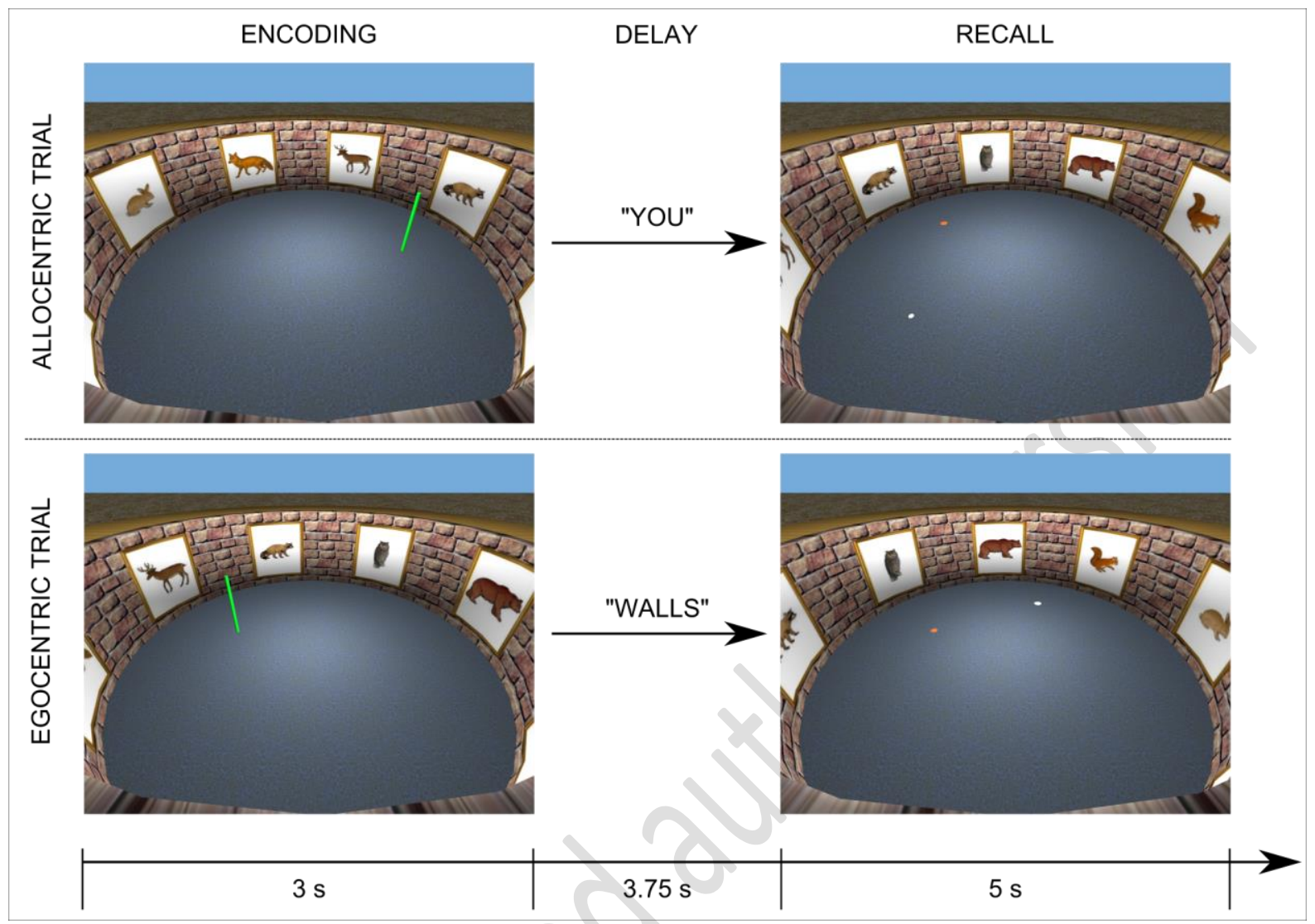


Figure 2

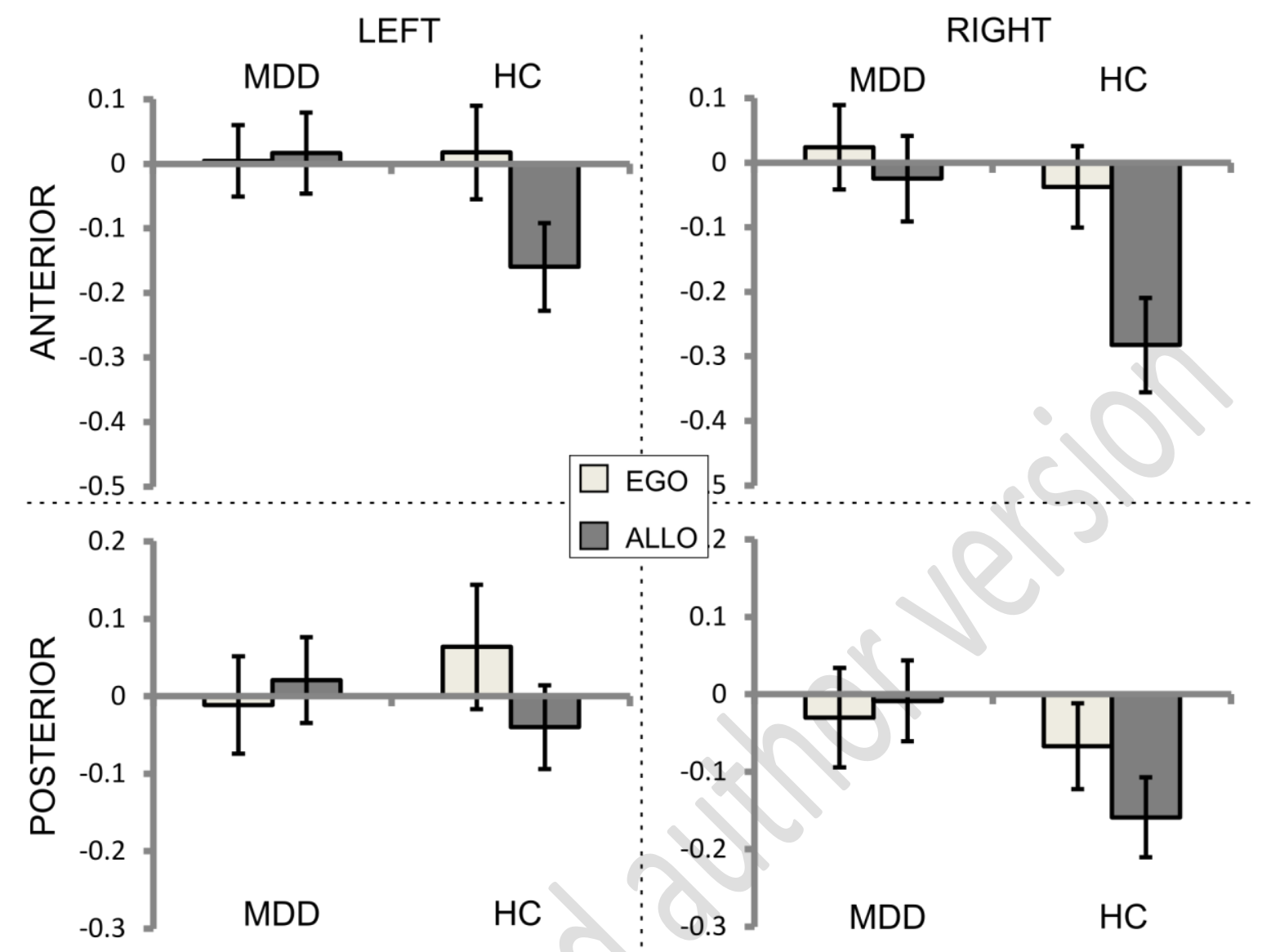


Table 1: Participant characteristics

\begin{tabular}{|c|c|c|c|}
\hline & Patients & Controls & group difference \\
\hline $\operatorname{Sex}(f / m)$ & $10 / 10$ & $12 / 8$ & $\operatorname{chi}^{2}=0.404 p=.525$ \\
\hline Age (years) & $45.3(11.9)$ & $42.6(12.1)$ & $t=0.725 p=.473$ \\
\hline BDI & $37.8(11.6)$ & $1.5(2.3)$ & $t=13.69 p<.001$ \\
\hline State anxiety & $47.2(13.0)$ & $30.2(10.8)$ & $t=4.450 p<.001$ \\
\hline Trait anxiety & $57.5(13.7)$ & $30.6(10.0)$ & $t=7.000 p<.001$ \\
\hline verbal IQ & $113.6(11.4)$ & $115.4(6.4)$ & $t=0.617 p=.541$ \\
\hline HAM-D & $23.5(5.4)$ & $0.15(0.67)$ & $t=19.24, p<.001$ \\
\hline Age of onset (years) & $28.3(15.0)$ & & \\
\hline Illness duration (years) & $10.4(9.4)$ & & \\
\hline $\begin{array}{l}\text { Number of episodes } \\
\text { mean (standard deviation) } \\
\text { median } \\
\text { min/max }\end{array}$ & $\begin{array}{l}3.87(3.49) \\
3 \\
1 / 11\end{array}$ & & \\
\hline previous hospitalizations (yes/no) & $3 / 17$ & & \\
\hline Medication & $\begin{array}{l}\text { none: } 1 \\
\text { SSRI: } 5 \\
\text { SSRI + other }{ }^{*}: 2 \\
\text { SNRI: } 2 \\
\text { SNRI + other }{ }^{*}: 6 \\
\text { atypical AD: } 1 \\
\text { TCA: } 1 \\
\text { other: } 2\end{array}$ & & \\
\hline
\end{tabular}

Means and standard deviations (in parentheses) of participant characteristics. SSRI=Selective Serotonin Reuptake Inhibitors, SNRI=Serotonin and Noradrenalin Reuptake Inhibitors, AD=Atypical antidepressants, TCA=Tricyclical antidepressants. *Other included Pregabalin, Lithium, Aripiprazole, Quetiapine. 
Table 2: Region-of-interest fMRI results of AvE contrast

\begin{tabular}{|l|l|l|l|l|}
\hline $\begin{array}{l}\text { Hippocampus } \\
\text { ROI }\end{array}$ & $\begin{array}{l}\text { Patients } \\
(\mathrm{n}=19)\end{array}$ & $\begin{array}{l}\text { Controls } \\
(\mathrm{n}=20)\end{array}$ & Condition effect & Group difference \\
\hline $\begin{array}{l}\text { Left } \\
\text { anterior }\end{array}$ & $0.016(0.189)$ & $-0.177(0.312)$ & $\mathrm{t}=-1.893, \mathrm{p}=.066$ & $\mathrm{t}=-2.325, \mathrm{p}=.025$ \\
\hline $\begin{array}{l}\text { Left } \\
\text { posterior }\end{array}$ & $0.031(0.251)$ & $-0.104(0.200)$ & $\mathrm{t}=-1.018, \mathrm{p}=.315$ & $\mathrm{t}=-1.853, \mathrm{p}=.072$ \\
\hline $\begin{array}{l}\text { Right } \\
\text { anterior }\end{array}$ & $-0.050(0.257)$ & $-0.245(0.301)$ & $\mathrm{t}=-3.180, \mathrm{p}=.003$ & $\mathrm{t}=-2.170, \mathrm{p}=.036$ \\
\hline $\begin{array}{l}\text { Right } \\
\text { posterior }\end{array}$ & $0.024(0.239)$ & $-0.032(0.177)$ & $\mathrm{t}=-1.019, \mathrm{p}=.314$ & $\mathrm{t}=-1.728, \mathrm{p}=.092$ \\
\hline
\end{tabular}

Means (and standard deviation) of the Allocentric-vs-Egocentric contrast of the retrieval phase. The condition effect column shows the result of a one-sample t-test of this contrast against 0 (across both groups). The group difference column shows the result of an independent-sample t-test for the difference between patients and healthy controls. This ttest did not assume equal variances. Bolded figures represent significant $(p<.05)$ results. 
Table 3: Results of neuropsychological testing

\begin{tabular}{|c|c|c|c|c|}
\hline & Patients & Controls & group difference & Effect size $\left(R^{2}\right)$ \\
\hline $\begin{array}{l}\text { Digit span } \\
\text { forward span } \\
\text { backward span } \\
\text { forward correct trials } \\
\text { backward correct trials } \\
\end{array}$ & $\begin{array}{l}6.35(1.31) \\
4.85(1.39) \\
7.80(2.33) \\
6.45(2.16) \\
\end{array}$ & $\begin{array}{l}7.40(1.19) \\
5.50(1.43) \\
9.75(2.26) \\
7.65(2.41)\end{array}$ & $\begin{array}{l}t=2.657, p=.011^{*} \\
t=1.458, p=.129 \\
\chi^{2}=11.51, p=.001^{*} \\
\chi^{2}=4.104, p=.043\end{array}$ & $\begin{array}{l}0.157 \\
0.053 \\
0.253 \\
0.098\end{array}$ \\
\hline $\begin{array}{l}\text { Rey auditory verbal-learning test } \\
\text { A1 (items correct) } \\
\text { A5 (items correct) } \\
\text { A1 to A5 (items correct) } \\
\text { B (items correct) } \\
\text { A6 (items correct) } \\
\text { A7 (items correct) } \\
\text { Recognition A (number of hits) } \\
\text { Recognition B (number of hits) }\end{array}$ & $\begin{array}{l}5.95(1.84) \\
10.7(3.50) \\
45.8(12.1) \\
5.63(2.11) \\
9.68(3.56) \\
8.33(4.13) \\
11.8(2.52) \\
7.58(3.44) \\
\end{array}$ & $\begin{array}{l}6.60(2.06) \\
12.8(1.99) \\
52.0(9.51) \\
6.00(1.86) \\
11.6(2.54) \\
11.2(3.17) \\
13.5(1.87) \\
9.42(2.09) \\
\end{array}$ & $\begin{array}{l}\chi^{2}=1.136, p=.287 \\
\chi^{2}=15.98, p<.001^{*} \\
\chi^{2}=21.67, p<.001^{*} \\
\chi^{2}=0.371, p=.542 \\
\chi^{2}=10.84, p=.001^{*} \\
\chi^{2}=20.66, p<.001^{*} \\
\chi^{2}=12.32, p<.001^{*} \\
\chi^{2}=8.704, p=.003^{*}\end{array}$ & $\begin{array}{l}0.028 \\
0.340 \\
0.420 \\
0.009 \\
0.241 \\
0.409 \\
0.278 \\
0.197 \\
\end{array}$ \\
\hline $\begin{array}{l}\text { Spatial working memory } \\
\text { 2D between-search errors } \\
\text { 3D between-search errors }\end{array}$ & $\begin{array}{l}228.4(90.3) \\
249.9(114.1)\end{array}$ & $\begin{array}{l}168.0(100.0) \\
156.5(103.5)\end{array}$ & $\begin{array}{l}t=2.005, p=.052 \\
t=2.519, p=.016^{*}\end{array}$ & $\begin{array}{l}0.096 \\
0.143 \\
\end{array}$ \\
\hline $\begin{array}{l}\text { Object relocation task } \\
\text { position-only memory (error) } \\
\text { object-location binding (\#correct) } \\
\text { combined process (error) }\end{array}$ & $\begin{array}{l}207.3(48.5) \\
12.5(4.26) \\
386.1(135.2)\end{array}$ & $\begin{array}{l}169.2(33.8) \\
14.4(3.86) \\
342.0(132.2)\end{array}$ & $\begin{array}{l}t=2.882, p=.006^{*} \\
\chi^{2}=8.121, p=.004^{*} \\
t=1.043, p=.304\end{array}$ & $\begin{array}{l}0.179 \\
0.184 \\
0.028\end{array}$ \\
\hline $\begin{array}{l}\text { Visual patterns test } \\
\text { maximum pattern size }\end{array}$ & $9.05(2.37)$ & $9.80(1.85)$ & $t=1.114, p=.273$ & 0.032 \\
\hline $\begin{array}{l}\text { Stroop task } \\
\quad \text { word reading (seconds) }\end{array}$ & $54.5(17.5)$ & 46.1 (7.9) & $\mathrm{t}=1.941, \mathrm{p}=.063$ & 0.090 \\
\hline
\end{tabular}




\begin{tabular}{|l|l|l|l|l|}
$\begin{array}{l}\text { color naming (seconds) } \\
\text { incongruent words (seconds) }\end{array}$ & $\begin{array}{l}77.3(21.0) \\
140.1(45.2)\end{array}$ & $\begin{array}{l}66.3(11.7) \\
115.5(38.6)\end{array}$ & $\mathrm{t}=2.040, \mathrm{p}=.050$ & 0.099 \\
$\mathrm{t}=1.851, \mathrm{p}=.072$ & 0.083 \\
\hline $\begin{array}{l}\text { Trail making test } \\
\text { A (seconds) }\end{array}$ & $35.4(9.51)$ & $27.6(8.69)$ & $\mathrm{t}=2.696, \mathrm{p}=.010^{*}$ & 0.161 \\
\hline $\mathrm{B}$ (seconds) & $68.9(26.6)$ & $51.8(17.0)$ & $\mathrm{t}=2.415, \mathrm{p}=.021^{*}$ & 0.133 \\
\hline B-A (seconds) & $33.4(22.3)$ & $24.2(14.1)$ & $\mathrm{t}=1.572, \mathrm{p}=.124$ & 0.061 \\
\hline
\end{tabular}

Means (and standard deviations) of neuropsychological task measures. Group differences were calculated with independent-samples t-tests, adjusted for unequal variance if necessary, or with Wald- $\chi^{2}$ tests as part of a generalized linear model with logit link function if the measure represented a count and was limited by the task. Effect sizes represent coefficients of determination of ordinary-least-squares general linear models and their equivalent based on maximum likelihood for generalized linear models. *Denotes significant effects following correction for multiple-comparison using a false-discovery-rate of $5 \%$. 
A. Finkelmeyer, J. Nilsson, J. He, L. Stevens, J. J. Maller, R. A. Moss, S. Small, P. Gallagher, K. Coventry, I. N. Ferrier, R. H. McAllister-Williams

\section{Altered hippocampal function in major depression despite intact structure and resting perfusion}

\section{Supplementary Material}

\section{Contents}

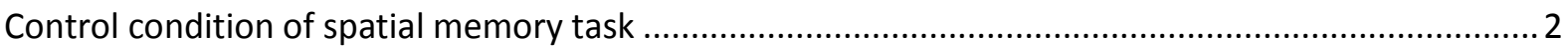

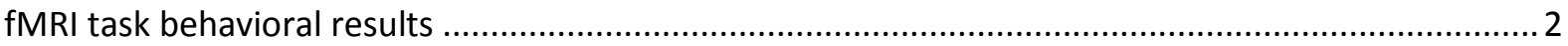

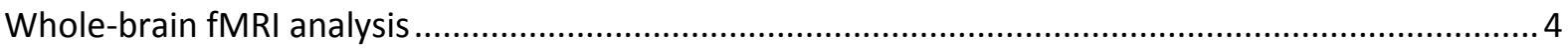

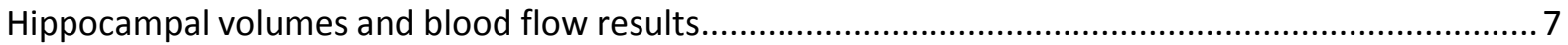

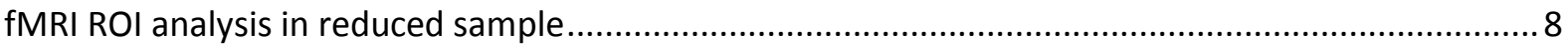




\section{Control condition of spatial memory task}

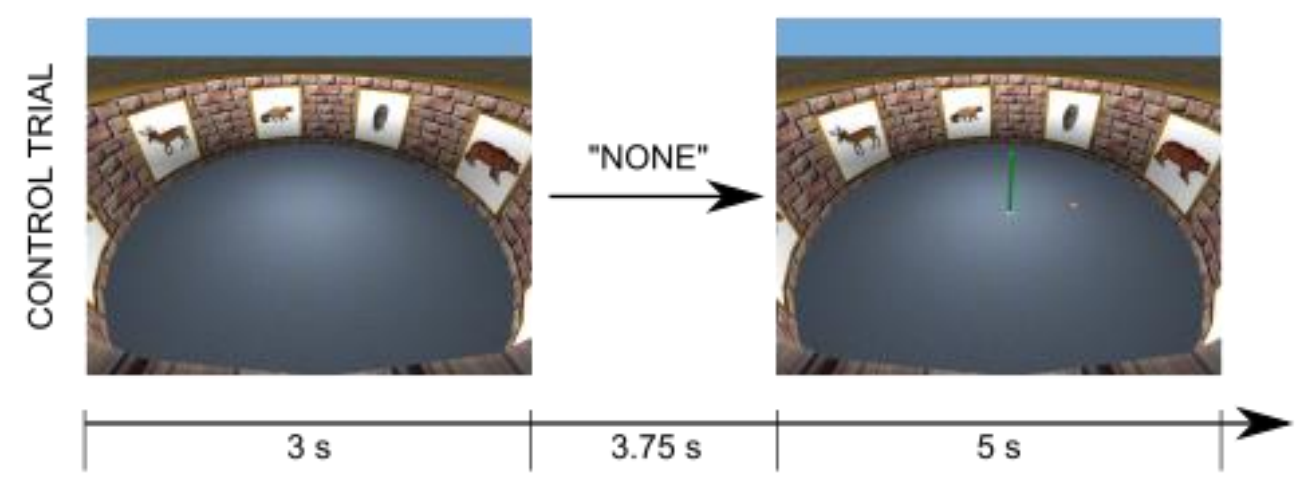

Figure S1: Trial structure of the control condition of the fMRI task. Only the empty arena with its landmarks was shown during encoding. During retrieval participants were instructed to press the button that corresponded to the disc that was indicated by the green pole marker.

\section{fMRI task behavioral results}

Table S1: Behavioral findings of fMRI task

\begin{tabular}{|c|c|c|c|c|c|}
\hline Source & SS & df & MS & $\mathrm{F}$ & $\mathrm{p}$ \\
\hline \multicolumn{6}{|l|}{ Errors } \\
\hline $\begin{array}{l}\text { Within-subject effects } \\
\quad \text { Condition (egocentric, allocentric) }\end{array}$ & 1.395 & 1 & 1.395 & 97.004 & $<.001$ \\
\hline Condition $\mathrm{x}$ group & 0.027 & 1 & 0.027 & 1.860 & .183 \\
\hline Error (condition) & .417 & 29 & 0.014 & & \\
\hline Rotation angle (45, 90, 135 degrees) & 0.519 & 2 & 0.259 & 22.388 & $<.001$ \\
\hline Angle $x$ group & 0.000 & 2 & 0.000 & 0.004 & .996 \\
\hline Error (angle) & 0.672 & 58 & 0.012 & & \\
\hline Condition $\mathrm{x}$ angle & 0.379 & 2 & 0.189 & 13.296 & $<.001$ \\
\hline Condition $\mathrm{x}$ angle $\mathrm{x}$ group & 0.067 & 2 & 0.034 & 2.354 & .104 \\
\hline Error (condition $\mathrm{x}$ angle) & 0.826 & 58 & 0.014 & & \\
\hline $\begin{array}{l}\text { Between-subject effects } \\
\text { Group }\end{array}$ & 0.115 & 1 & 0.115 & 1.477 & .234 \\
\hline Between & 2.266 & 29 & 0.078 & & \\
\hline \multicolumn{6}{|l|}{ Response Time } \\
\hline $\begin{array}{l}\text { Within-subject effects } \\
\quad \text { Condition (egocentric, allocentric) }\end{array}$ & 34.702 & 1 & 34.702 & 63.550 & $<.001$ \\
\hline Condition x Group & 0.663 & 1 & 0.663 & 1.212 & .280 \\
\hline Error (condition) & 15.836 & 29 & 0.546 & & \\
\hline Rotation angle $(45,90,135$ degrees $)$ & 2.339 & 2 & 1.169 & 16.705 & $<.001$ \\
\hline Angle $x$ group & 0.211 & 2 & 0.105 & 1.506 & .230 \\
\hline Error (angle) & 4.060 & 58 & 0.070 & & \\
\hline Condition $\mathrm{x}$ angle & 0.572 & 2 & 0.286 & 3.690 & 0.031 \\
\hline
\end{tabular}


ALTERED HIPPOCAMPAL FUNCTION IN DEPRESSION (SUPPL) - 3

\begin{tabular}{|l|r|r|r|r|r|}
\hline Condition $\mathrm{x}$ angle $\mathrm{x}$ group & 0.378 & 2 & 0.189 & 2.438 & 0.096 \\
\hline Error (condition $\mathrm{x}$ angle) & 4.499 & 58 & 0.078 & & \\
\hline $\begin{array}{l}\text { Between- subject effects } \\
\text { Group }\end{array}$ & 0.977 & 1 & 0.977 & 0.779 & .385 \\
\hline Between & 36.378 & 29 & 1.254 & & \\
\hline
\end{tabular}

$\mathrm{SS}=$ Sum of square, $\mathrm{df}=$ degrees of freedom, MS=mean square; Results with $p<.05$ in bold.

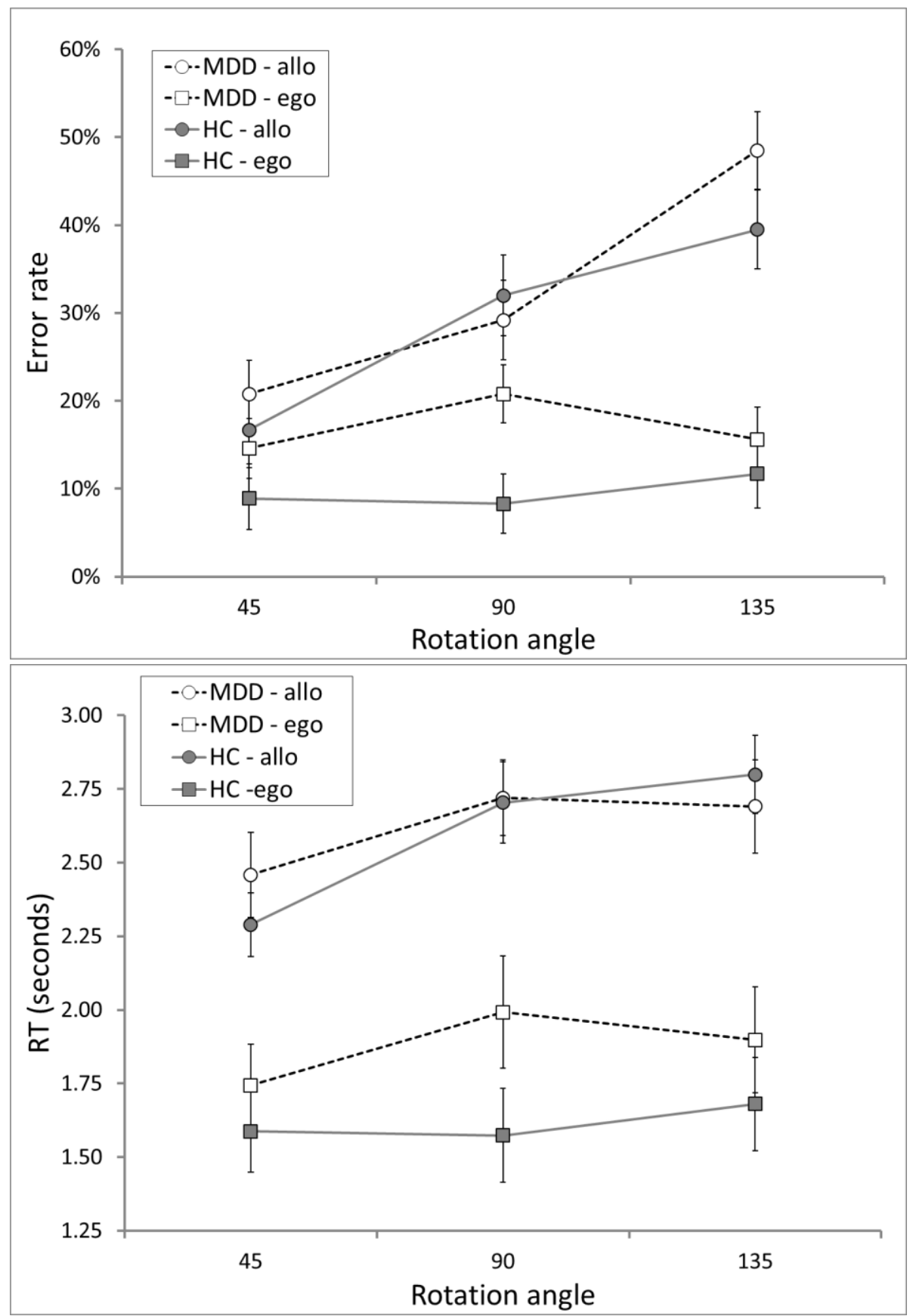

Figure S1: Behavioral findings of $\mathrm{AMRI}$ task (as presented in ANOVA results, table S1). Mean error rates (top) and mean reaction times (bottom). Error bars are $+/-1$ standard error of mean. 
Whole-brain fMRI analysis

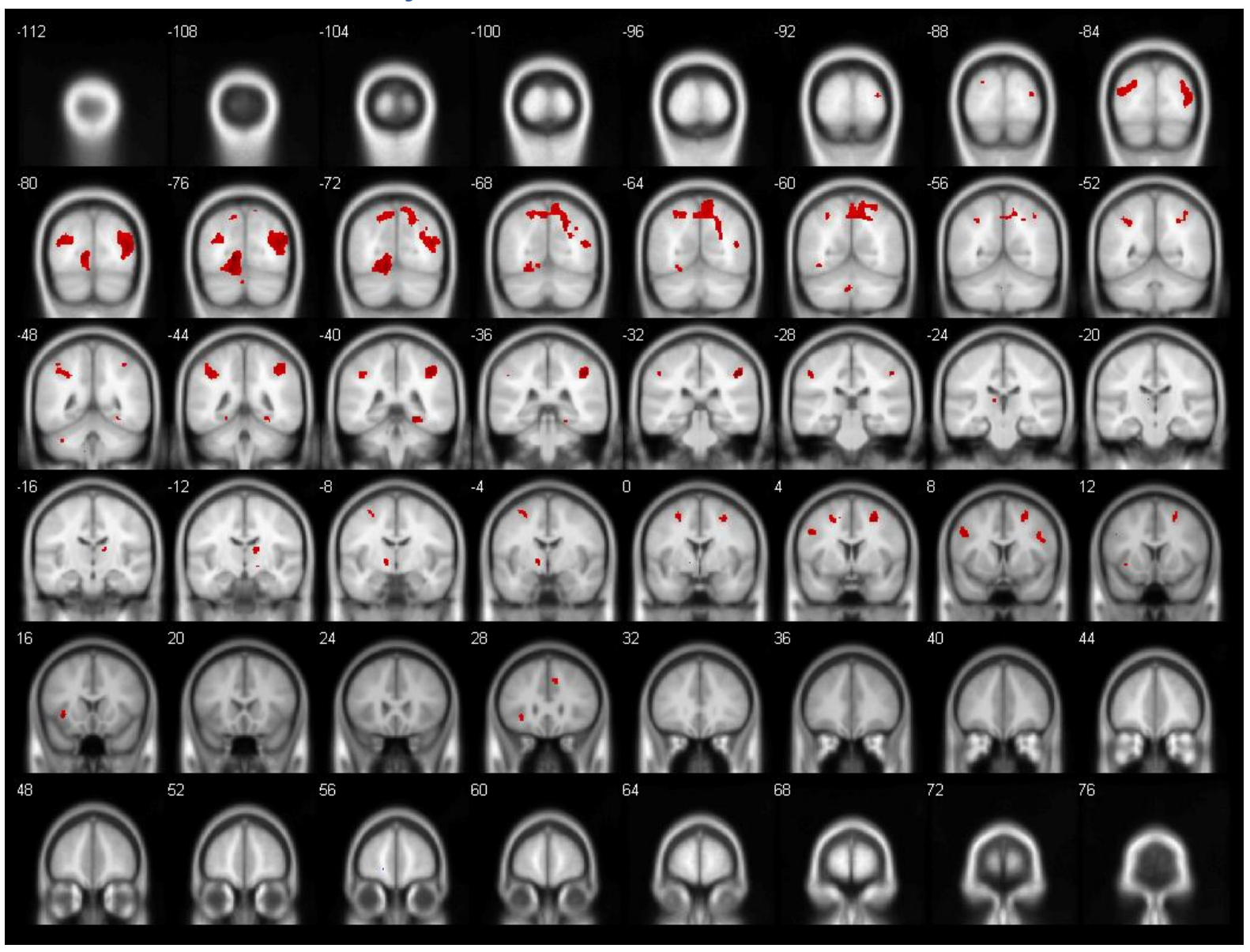

Figure S3: Results of whole-brain analysis of AvE contrast across the entire sample ( $p<.05$, FWEcorrected). Areas in red show significant BOLD signal differences in the positive direction (i.e. allocentric condition > egocentric condition), whereas the area in blue show significant differences in the negative direction (allocentric < egocentric). 


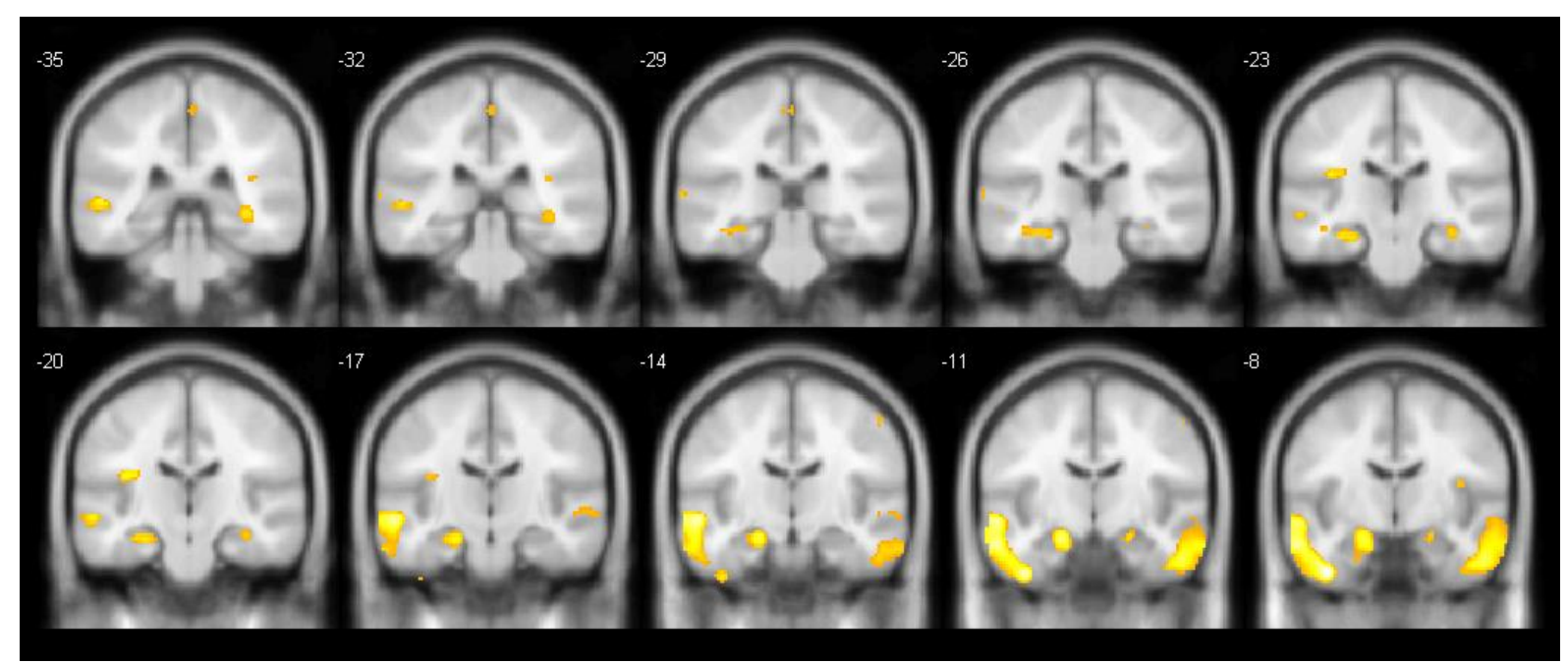

Figure S4: Pattern of findings from the whole-brain analysis of negative AvE contrast (Egocentric > Allocentric) in the healthy control group only $(p<.005$, uncorrected) in the hippocampal region. No hippocampal differences were seen at this level in patients. 
Table S2: Whole-brain fMRI results

\begin{tabular}{|c|c|c|c|c|}
\hline $\begin{array}{l}\text { cluster size } \\
\text { (voxels) }\end{array}$ & Peak location & $\begin{array}{c}\text { Peak MNI } \\
\text { coordinates }(\mathrm{mm})\end{array}$ & Peak T & $\begin{array}{c}\text { Peak p-value } \\
\text { (FWE) }\end{array}$ \\
\hline \multicolumn{5}{|c|}{ positive AvE contrast (Allocentric > Egocentric) ${ }^{*}$} \\
\hline \multirow[t]{2}{*}{609} & L Lingual Gyrus & $-12,-76,0$ & 7.207 & $<0.001$ \\
\hline & L Lingual Gyrus & $-12,-72,-10$ & 6.860 & 0.001 \\
\hline \multirow[t]{3}{*}{2611} & R Supramarginal Gyrus & $46,-32,42$ & 7.119 & $<0.001$ \\
\hline & R Inferior Parietal Lobule & $40,-40,46$ & 6.595 & 0.002 \\
\hline & R Middle Occipital Gyrus & $40,-78,16$ & 6.513 & 0.003 \\
\hline 67 & R Fusiform Gyrus & $24,-40,-12$ & 6.640 & 0.002 \\
\hline 143 & R Superior Frontal Gyrus & $26,4,52$ & 6.587 & 0.002 \\
\hline \multirow[t]{3}{*}{312} & L Middle Occipital Gyrus & $-38,-80,20$ & 6.374 & 0.004 \\
\hline & L Middle Occipital Gyrus & $-28,-76,20$ & 5.880 & 0.016 \\
\hline & L Superior Occipital Gyrus & $-24,-86,28$ & 5.832 & 0.018 \\
\hline 91 & L Precentral Gyrus & $-48,8,34$ & 6.372 & 0.004 \\
\hline 29 & L Insula & $-34,14,-2$ & 6.293 & 0.005 \\
\hline 45 & L Globus Pallidus & $-12,-4,0$ & 6.258 & 0.005 \\
\hline 40 & L Inferior Parietal Lobule & $-50,-28,42$ & 6.226 & 0.006 \\
\hline \multirow[t]{3}{*}{93} & L Mid Frontal Gyrus & $-26,0,54$ & 6.052 & 0.010 \\
\hline & L Precentral Gyrus & $-30,-6,58$ & 5.751 & 0.022 \\
\hline & L Superior Frontal Gyrus & $-14,4,52$ & 5.614 & 0.031 \\
\hline 40 & R Thalamus & $14,-12,14$ & 6.037 & 0.011 \\
\hline 27 & L Cerebellum Vermis & $-4,-60,-36$ & 5.959 & 0.013 \\
\hline \multirow[t]{2}{*}{38} & R Inferior Frontal Operculum & $48,8,24$ & 5.756 & 0.022 \\
\hline & R Inferior Frontal Operculum & $42,8,32$ & 5.601 & 0.033 \\
\hline \multicolumn{5}{|c|}{ negative AvE contrast (Egocentric > Allocentric) ${ }^{*}$} \\
\hline \multicolumn{5}{|c|}{ (no significant clusters) } \\
\hline \multicolumn{5}{|c|}{ 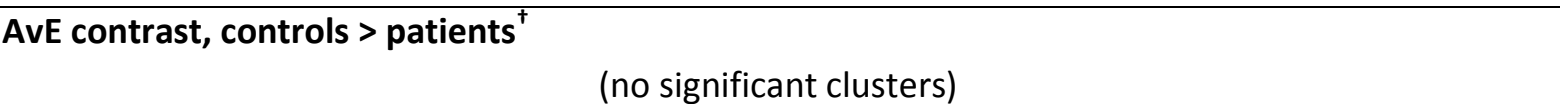 } \\
\hline \multicolumn{5}{|c|}{ AvE contrast, patients $>$ controls $^{\dagger}$} \\
\hline \multicolumn{5}{|c|}{ (no significant clusters) } \\
\hline
\end{tabular}




\section{Hippocampal volumes and blood flow results}

Table S3: Hippocampal Volumes

\begin{tabular}{|l|r|r|r|r|l|}
\hline & \multicolumn{2}{|c|}{ Patients } & \multicolumn{2}{c|}{ Controls } & Controls vs Patients \\
& $\mathrm{ml}$ & \multicolumn{1}{|c|}{$\begin{array}{c}\text { \%TICV } \\
\text { (\%TICV, df=38) }\end{array}$} \\
\hline L anterior & 3.154 & 0.2230 & 2.947 & 0.2158 & $\mathrm{t}=-1.001, \mathrm{p}=.323$ \\
ROI & $(0.090)$ & $(0.0051)$ & $(0.082)$ & $(0.0051)$ & \\
\hline L posterior & 0.371 & 0.0263 & 0.347 & 0.0254 & $\mathrm{t}=-0.399, \mathrm{p}=.692$ \\
ROI & $(0.019)$ & $(0.0013)$ & $(0.024)$ & $(0.0018)$ & \\
\hline R anterior & 2.873 & 0.2034 & 2.715 & 0.1983 & $\mathrm{t}=-0.695, \mathrm{p}=.492$ \\
ROI & $(0.089)$ & $(0.0058)$ & $(0.084)$ & $(0.0043)$ & \\
\hline R posterior & 0.375 & 0.0265 & 0.373 & 0.0273 & $\mathrm{t}=0.333, \mathrm{p}=.741$ \\
ROI & $(0.025)$ & $(0.0017)$ & $(0.026)$ & $(0.0019)$ & \\
\hline L combined & 3.525 & 0.2493 & 3.942 & 0.2412 & $\mathrm{t}=-1.110, \mathrm{p}=.274$ \\
& $(0.042)$ & $(0.0235)$ & $(0.038)$ & $(0.0225)$ & \\
\hline R combined & 3.247 & 0.2299 & 3.088 & 0.2257 & $\mathrm{t}=-0.593, \mathrm{p}=.557$ \\
& $(0.043)$ & $(0.0275)$ & $(0.036)$ & $(0.0161)$ & \\
\hline Total & 6.772 & 0.4791 & 6.382 & 0.4669 & $\mathrm{t}=-0.900, \mathrm{p}=.374$ \\
& $(0.082)$ & $(0.0490)$ & $(0.072)$ & $(0.0363)$ & \\
\hline
\end{tabular}

Mean (standard deviations) hippocampal volumes in $\mathrm{ml}$ and as percentage of total intracranial volume (TICV). $\mathrm{R}=$ right, $\mathrm{L}=$ left, $\mathrm{ROI}=$ region of interest

Table S4: Regional cerebral blood flow results

\begin{tabular}{|l|r|r|r|r|l|l|}
\hline & \multicolumn{2}{|c|}{ Depressed $(\mathrm{n}=20)$} & \multicolumn{2}{|c|}{ Control $(\mathrm{n}=20)$} & \multicolumn{2}{l|}{ Significance } \\
region & males & females & males & females & group & sex \\
\hline L anterior & 34.90 & 46.46 & 40.19 & 47.95 & $\mathrm{~F}=0.81, \mathrm{p}=.360$ & $\mathrm{~F}=7.18, \mathrm{p}=.011$ \\
hippocampus & $(8.20)$ & $(13.3)$ & $(12.2)$ & $(11.1)$ & & \\
\hline L posterior & 44.89 & 53.15 & 44.91 & 54.08 & $\mathrm{~F}=0.01, \mathrm{p}=.929$ & $\mathrm{~F}=2.77, \mathrm{p}=.105$ \\
hippocampus & $(17.8)$ & $(14.7)$ & $(13.2)$ & $(15.3)$ & & \\
\hline R anterior & 34.07 & 49.49 & 41.79 & 46.17 & $\mathrm{~F}=0.21, \mathrm{p}=.649$ & $\mathrm{~F}=6.29, \mathrm{p}=.017$ \\
hippocampus & $(9.91)$ & $(14.7)$ & $(13.4)$ & $(10.3)$ & & \\
\hline R posterior & 35.53 & 60.20 & 47.11 & 48.42 & $\mathrm{~F}=0.01, \mathrm{p}=.985$ & $\mathrm{~F}=5.13, \mathrm{p}=.030$ \\
hippocampus & $(11.2)$ & $(17.5)$ & $(16.3)$ & $(17.9)$ & & \\
\hline GM & 28.94 & 45.17 & 34.59 & 42.65 & $\mathrm{~F}=0.17, \mathrm{p}=.574$ & $\mathrm{~F}=19.04, \mathrm{p}<.001$ \\
& $(6.83)$ & $(9.83)$ & $(6.92)$ & $(9.82)$ & & \\
\hline WM & 17.96 & 26.91 & 22.46 & 26.88 & $\mathrm{~F}=1.16, \mathrm{p}=.287$ & $\mathrm{~F}=12.99, \mathrm{p}=.001$ \\
& $(4.50)$ & $(7.45)$ & $(4.22)$ & $(6.09)$ & & \\
\hline
\end{tabular}

Means (and standard deviation) of regional CBF in $\mathrm{ml} / 100 \mathrm{~g} / \mathrm{min}$ of the different brain regions. The last two columns show $p$-values for ANOVAs with group and sex as fixed factors. L=left, $R=$ right, $\mathrm{GM}=$ gray matter, $\mathrm{WM}=$ white matter 


\section{fMRI ROI analysis in reduced sample}

Table S5: Region-of-interest fMRI results of AvE contrast

\begin{tabular}{|l|l|l|l|l|}
\hline $\begin{array}{l}\text { Hippocampus } \\
\text { ROI }\end{array}$ & $\begin{array}{l}\text { Patients } \\
(\mathrm{n}=16)\end{array}$ & $\begin{array}{l}\text { Controls } \\
(\mathrm{n}=15)\end{array}$ & Condition effect & Group difference \\
\hline $\begin{array}{l}\text { Left } \\
\text { anterior }\end{array}$ & $-0.017(0.177)$ & $-0.243(0.335)$ & $\mathrm{t}=-2.46, \mathrm{p}=.020$ & $\mathrm{t}=-2.316, \mathrm{p}=.031$ \\
\hline $\begin{array}{l}\text { Left } \\
\text { posterior }\end{array}$ & $-0.008(0.252)$ & $-0.094(0.218)$ & $\mathrm{t}=-1.17, \mathrm{p}=.252$ & $\mathrm{t}=-1.016, \mathrm{p}=.318$ \\
\hline Right anterior & $-0.069(0.268)$ & $-0.310(0.313)$ & $\mathrm{t}=-3.23, \mathrm{p}=.002$ & $\mathrm{t}=-2.291, \mathrm{p}=.030$ \\
\hline Right posterior & $-0.001(0.249)$ & $-0.077(0.190)$ & $\mathrm{t}=-0.92, \mathrm{p}=.364$ & $\mathrm{t}=-0.992, \mathrm{p}=.330$ \\
\hline
\end{tabular}

Means (and standard deviation) of the Allocentric-vs-Egocentric contrast of the retrieval phase. The condition effect column shows the result of a one-sample t-test of this contrast against 0 (across both groups). The group difference column shows the result of an independent-sample t-test for the difference between patients and healthy controls. This t-test did not assume equal variances. Bolded figures represent significant $(p<.05)$ results.

Table S6: Participant characteristics (reduced sample)

\begin{tabular}{|l|l|l|l|}
\hline & Patients & Controls & group difference \\
\hline Sex $(\mathrm{f} / \mathrm{m})$ & $7 / 9$ & $7 / 8$ & $\chi^{2}=0.027 \mathrm{p}=.870$ \\
\hline Age (years) & $44.0(12.9)$ & $40.8(12.0)$ & $\mathrm{t}=0.713 \mathrm{p}=.481$ \\
\hline BDI & $38.6(11.4)$ & $1.6(2.6)$ & $\mathrm{t}=12.32 \mathrm{p}<.001$ \\
\hline State anxiety & $47.6(13.8)$ & $28.6(9.3)$ & $\mathrm{t}=4.449 \mathrm{p}<.001$ \\
\hline Trait anxiety & $59.0(12.7)$ & $29.9(9.2)$ & $\mathrm{t}=7.188 \mathrm{p}<.001$ \\
\hline verbal IQ & $112.3(11.9)$ & $114.1(5.7)$ & $\mathrm{t}=0.557 \mathrm{p}=.582$ \\
\hline HAM-D & $23.3(5.4)$ & $0.0(0.0)$ & $\mathrm{t}=16.59, \mathrm{p}<.001$ \\
\hline
\end{tabular}

